\title{
Health Effects and Exposure Assessment to Bioaerosols in Indoor and Outdoor Environments
}

\author{
Ewa Brągoszewska (D)
}

check for updates

Citation: Bragoszewska, E. Health Effects and Exposure Assessment to Bioaerosols in Indoor and Outdoor Environments. Atmosphere 2021, 12, 359. https://doi.org/10.3390/ atmos12030359

Received: 5 March 2021

Accepted: 8 March 2021

Published: 9 March 2021

Publisher's Note: MDPI stays neutral with regard to jurisdictional claims in published maps and institutional affiliations.

Copyright: (c) 2021 by the author. Licensee MDPI, Basel, Switzerland. This article is an open access article distributed under the terms and conditions of the Creative Commons Attribution (CC BY) license (https:// creativecommons.org/licenses/by/ $4.0 /)$.
Department of Technologies and Installations for Waste Management, Faculty of Energy and Environmental Engineering, Silesian University of Technology, 18 Konarskiego St., 44-100 Gliwice, Poland; ewa.bragoszewska@polsl.pl

The Atmosphere Special Issue entitled "Health Effects and Exposure Assessment to Bioaerosols in Indoor and Outdoor Environments" comprises five original papers.

Air pollution, due to natural and anthropogenic sources, generates an enormous environmental cost. The issue of healthy living spaces and good air quality is a global concern, because individuals inhale 15,000 L of air every $24 \mathrm{~h}$. Thus, contemporary monitoring and reducing exposure to air pollutants presents a particular challenge for us. One of the crucial indicators of indoor and outdoor air quality is bioaerosols. They play an instrumental role as risk factors when it comes to adverse health outcome. These indicators, also known as primary biological airborne particles (PBAPs), have been linked to various health effects such as infectious diseases, toxic effects, allergies, and even cancer. PBAPs include all particles with a biological source in suspension in the air (bacteria, fungi, viruses, pollen), as well as biomolecules (toxins, debris from membranes). To foster our current scientific knowledge about bioaerosols, scientific research studies related to the characteristics of biological aerosols in indoor and outdoor environments, the methods used to improve air quality, as well as the health effects of and exposure assessment to bioaerosols problem, have been collected in this Special Issue.

The first paper in this Special Issue applied the monitoring of PBAPs collected in a high school gymnastic hall located in an urban area of Poland. Bragoszewska et al. [1] indicated that the concentrations of bacterial aerosol in the analysed high school gym in the naturally ventilated historic building were not particularly hazardous for the occupants; however, the share of the respirable fraction (particles with an aerodynamic diameter less than 3.3 $\mu \mathrm{m}$ ) increased during sports activities from $30 \%$ (before gymnastic classes) to $80 \%$ of the total concentration of bacterial aerosol during physical activities. The highest antibiotic resistance was revealed to be Staphylococcus epidermis (isolated during gymnastic classes) and Pseudomonas sp. (isolated before gymnastic classes). The results of this study may indicate the usefulness of periodic PBAPs monitoring to verify the quality of the air and to establish possible technologically achievable guide levels of contamination for educational buildings. Małecka-Adamowicz et al. [2] presented a study about evaluating PBAPs in libraries, cafeterias, and selected classrooms of two schools in northern Poland and determined the antibiotic resistance of Staphylococcal strains isolated from the indoor air. A statistically significant relationship between the size of the rooms and the concentration of heterotrophic bacteria was observed. In both schools, higher microbial concentrations were recorded in smaller rooms (the cafeterias). The antibiograms indicated that resistance to erythromycin was common in $62.5 \%$ of the isolated staphylococcal strains. Levofloxacin and gentamicin were the most effective antibiotics. Given the current lack of precise indoor air quality guidelines in Poland, the research may be a very valuable contribution. ZenderŚwiercz [3] focused on analysing internal air parameters in an office room equipped with a decentralized façade ventilation device. The analyses of both temperature and humidity have proven that the values of inside air temperature and humidity are not affected by the temperature and humidity of outside air. In this case, the negative pressure generated 
during the exhaust cycle must induce an inflow of warm and dry air from an adjacent room. Skowron et al. [4] presented an assessment of the efficiency of radiant catalytic ionization (RCI) in eliminating enterococci resistant to selected antibiotics in the air compared to the antibiotic-susceptible strain, antibiotic-resistant, toxinogenic Clostridioides difficile in comparison with the non-toxinogenic, antibiotic-susceptible strain and elimination of Staphylococcus aureus non-MRSA and MRSA strain. The obtained results indicate that the use of RCI may contribute to reducing the occurrence of dangerous pathogens (including MRSA) in the indoor air, and perhaps transmission and persistence in the environment; thus, it is worth noticing that the RCI device should be taken into account in the designing of ventilation systems. Bragoszewska et al. [5] introduced methods to improve indoor air quality using air purifiers with high-efficiency particulate air filters (HEPA) that remove PBAPs from indoor environments. The reduction in total concentration of fungal aerosol in the presented study even when air purifiers were active was at a level of $42 \%$. The current findings suggested the need for further work, particularly focused on a re-emission process generated by air blown from air purifiers. The elucidation of this relationship will be an important foundation from which to develop air cleaning technologies. Moreover, this study shows the need for implementing a strategy to control and improve PBAP air quality in indoor environments.

The goal of this Special Issue was to present research with a wide perspective, involving air quality research studies, and the five papers in this Special Issue achieve. I hope that the results presented in this Special Issue will spur investigations in this area for more invigorating research in the future.

Funding: This research received no external funding.

Acknowledgments: The editor would like to thank the authors for their contributions, the reviewers for their helpful comments, and the Editorial Office for the support in publishing this Special Issue.

Conflicts of Interest: The author declares no conflict of interest.

\section{References}

1. Bragoszewska, E.; Biedroń, I.; Mainka, A. Microbiological Air Quality in a Highschool Gym Located in an Urban Area of Southern Poland-Preliminary Research. Atmosphere 2020, 11, 797. [CrossRef]

2. Małecka-Adamowicz, M.; Koim-Puchowska, B.; Dembowska, E.A. Diversity of Bioaerosols in Selected Rooms of Two Schools and Antibiotic Resistance of Isolated Staphylococcal Strains (Bydgoszcz, Poland): A Case Study. Atmosphere 2020, 11, 1105. [CrossRef]

3. Zender-Świercz, E. Microclimate in Rooms Equipped with Decentralized Façade Ventilation Device. Atmosphere 2020, 11, 800. [CrossRef]

4. Skowron, K.; Grudlewska-Buda, K.; Kożuszko, S.; Wiktorczyk, N.; Skowron, K.J.; Mikucka, A.; Bernaciak, Z.; GospodarekKomkowska, E. Efficacy of Radiant Catalytic Ionization in Reduction of Enterococcus spp., Clostridioides difficile and Staphylococcus aureus in Indoor Air. Atmosphere 2020, 11, 764. [CrossRef]

5. Bragoszewska, E.; Bogacka, M.; Pikoń, K. Effectiveness and Eco-Costs of Air Cleaners in Terms of Improving Fungal Air Pollution in Dwellings Located in Southern Poland-A Preliminary Study. Atmosphere 2020, 11, 1255. [CrossRef] 